\title{
Use of spent foundry sand and fly ash for the development of green self-consolidating concrete
}

\author{
Mustafa Şahmaran • Mohamed Lachemi • \\ Tahir K. Erdem • Hasan Erhan Yücel
}

Received: 13 September 2009/Accepted: 8 November 2010/Published online: 17 November 2010

(C) RILEM 2010

\begin{abstract}
In the United States alone, the foundry industry discards up to 10 million tons of sand each year, offering up a plentiful potential resource to replace sand in concrete products. However, because the use of spent foundry sand (SFS) is currently very limited in the concrete industry, this study investigates whether SFS can successfully be used as a sand replacement material in cost-effective, green, selfconsolidating concrete (SCC). In the study, SCC mixtures were developed to be even more inexpensive and environmentally friendly by incorporating Portland cement with fly ash (FA). Tests done on SCC mixtures to determine fresh properties (slump flow diameter, slump flow time, V-funnel flow time, yield stress, and relative viscosity), compressive strength, drying shrinkage and transport properties (rapid chloride permeability and volume of permeable pores) show that replacing up to $100 \%$ of sand with SFS and up to $70 \%$ Portland cement with FA enables the manufacture of green, lower cost SCC
\end{abstract}

M. Şahmaran · H. E. Yücel

Department of Civil Engineering, Gaziantep University, Gaziantep, Turkey

M. Lachemi ( $\square)$

Department of Civil Engineering, Ryerson University,

Toronto, ON, Canada

e-mail: mlachemi@ryerson.ca

T. K. Erdem

Department of Civil Engineering, Izmir Institute of Technology, Izmir, Turkey mixtures with proper fresh, mechanical and durability properties. The beneficial effects of FA compensate for some possible detrimental effects of SFS.

Keywords Fly ash · Foundry sand .

Self consolidating concrete $\cdot$ Mechanical properties · Durability

\section{Introduction}

Foundry sand is a high quality silica sand used as a molding material by ferrous and non-ferrous metal casting industries. It can be reused several times in foundries but, after a certain period, cannot be used further and becomes waste material, referred to as used or spent foundry sand (UFS or SFS). The majority of spent molding sands are classified as nonhazardous waste (i.e. not corrosive, ignitable, reactive or toxic). In a recent study, Siddique et al. [1] reported that in the United States alone, up to 10 million tons of foundry sand are discarded annually and are available for recycling. Siddique and Noumowe [2] listed more than ten application fields of SFSs; a summary of these applications can be found in References [1, 3, 4]. Examples of civil engineering applications that use SFS include landfills, highways and concrete production.

In conventional concrete production, SFS is used as a partial replacement material for fine aggregate. 
Siddique et al. [5] replaced up to $30 \%$ of the sand in concrete with SFS. The concrete mixtures prepared with SFS had higher compressive strength, split tensile strength and modulus of elasticity than the control mixtures without SFS. All of these properties increased with an increase in SFS content; similar results were obtained in an additional study by Siddique et al. [1]. Flexural strength also increased with an increase in SFS content. The study concluded that SFS could be conveniently used in making good quality concrete.

Khatib and Ellis [6] replaced up to $100 \%$ of the sand with SFS and observed a resulting strength loss; drying shrinkage increased with an increase in SFS content. Naik et al. [7] investigated compressive strength and freezing and thawing resistance of concrete blocks, bricks and paving stones by replacing sand with 25 and $35 \%$ SFS. Strength losses were observed in the SFS mixtures, but, almost all mixtures satisfied minimum compressive strength requirements in standard specifications for concrete bricks and blocks. On the other hand, partial replacement of sand with SFS reduced freezing and thawing resistance significantly. In a similar study by Naik et al. [4], water absorption values for concrete blocks made with used/new foundry sands were either comparable to or lower than blocks made with regular sand. Abrasion resistance of the paving stone specimens was found to be very high. Bakis et al. [8] prepared asphalt concrete in which $0-20 \%$ of the sand was replaced with SFS. In their study, the indirect tensile strength decreased almost linearly with an increase in SFS amount. Fiore and Zanetti [9] recommended using different SFS sizes for different applications; a size fraction between 0.1 and $0.025 \mathrm{~mm}$ was recommended for the concrete industry. A recent study by Kraus et al. [10] used foundry silica-dust as a replacement material for FA in the manufacture of self-consolidating concrete (SCC). Foundry silica-dust replaced with Class $\mathrm{C}$ fly ash by up to $30 \%$; some reduction in 3-day compressive strength and a considerable reduction in 28-day compressive strength were observed.

Despite the huge amounts of SFS being produced by foundries, studies on the use of SFS in the concrete industry are limited. The importance of recycling industrial by-products for green concrete and sustainable development is obvious. Because SCC is becoming a more widely used material and (to the best knowledge of the authors) there is no published study on the use of SFS as a sand replacement material in SCC, further investigations are necessary to encourage its use. This study investigates whether SFS can successfully be used to replace sand in SCC production, considering its performance at both fresh and hardened states.

Fly ash (FA) is another by-product used as cement replacement. The environmental benefits of recycling FA have been well-known for a number of years [11, 12], and the material has become a vital component in the manufacture of green concrete. Not only does the use of FA protect the environment, it improves a number of concrete properties, resulting in better workability, higher ultimate strengths, increased durability and lower shrinkage. Recycled materials such as FA and SFS have another key benefit: they also reduce the cost of SCC. Therefore, the purpose of this study is to produce green and cost-effective SCC by replacing sand and Portland cement with industrial by-products.

It is assumed that the beneficial effects of FA can compensate for the possible side effects of SFS, enabling SCC to maintain proper properties. In this study, 0-70\% of Portland cement was replaced with FA, and 0-100\% sand was replaced with SFS. Properties investigated were slump flow diameter, slump flow time, V-funnel flow time, rheological parameters (yield stress and plastic viscosity), compressive strength, rapid chloride permeability, drying shrinkage and volume of permeable pores.

\section{Experimental program}

\subsection{Materials}

The cement used in all SCC mixtures was an ordinary Portland cement (PC), equivalent to ASTM Type I Portland cement. A low-lime fly ash (FA) was used as a replacement material for PC. The chemical composition and physical properties of both the PC and FA are presented in Table 1. Particle size distribution of PC and FA is shown in Fig. 1. A polycarboxylicether type high range water reducing admixture (HRWR) with a solid content of $30 \%$ was used in all SCC mixtures. The coarse aggregate used was crushed limestone with a maximum aggregate size of $19 \mathrm{~mm}$, a water absorption capacity of $1.81 \%$ and saturated surface dry (SSD) bulk specific gravity of 
Table 1 Chemical composition and physical properties of Portland cement and fly ash

\begin{tabular}{lcc}
\hline Chemical composition (\%) & PC & FA \\
\hline $\mathrm{CaO}$ & 61.80 & 5.57 \\
$\mathrm{SiO}_{2}$ & 19.40 & 59.50 \\
$\mathrm{Al}_{2} \mathrm{O}_{3}$ & 5.30 & 22.20 \\
$\mathrm{Fe}_{2} \mathrm{O}_{3}$ & 2.30 & 3.90 \\
$\mathrm{MgO} \mathrm{O}$ & 0.95 & - \\
$\mathrm{SO}_{3}$ & 3.80 & 0.19 \\
$\mathrm{~K}_{2} \mathrm{O}$ & 1.10 & 1.11 \\
$\mathrm{Na}_{2} \mathrm{O}$ & 0.20 & 2.75 \\
Loss on ignition & 2.10 & 0.21 \\
$\mathrm{Physical}$ properties & & \\
Specific gravity & 3.15 & 2.18 \\
Retained on $45 \mu \mathrm{m}(0.002$ in.) $(\%)$ & 12.9 & 9.6 \\
Water requirement $(\%)$ & - & 93.4 \\
\hline
\end{tabular}

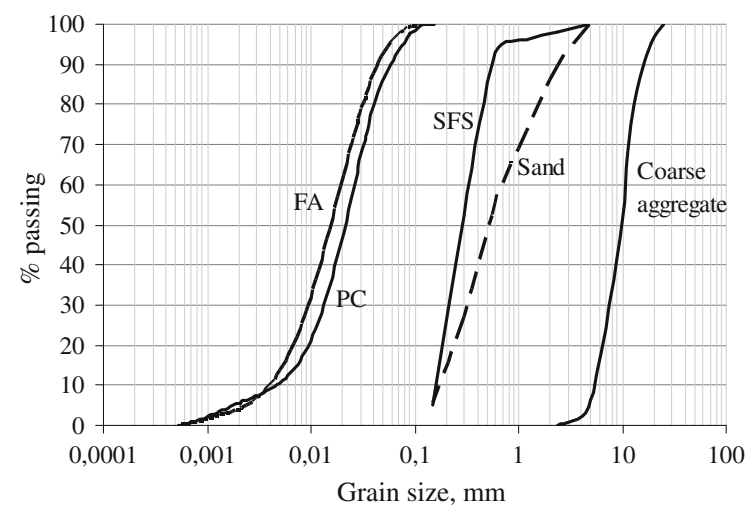

Fig. 1 Particle size distribution of PC, FA and aggregates

2.66. The regular sand used was natural river sand with a water absorption capacity of $4.94 \%$ and SSD bulk specific gravity of 2.35 .

The SFS was obtained from McCoy Foundry Co., Canada. It had a water absorption capacity of $1.60 \%$, an SSD bulk specific gravity of 2.55, and a dark grey color (Fig. 2). Chemical composition of the SFS is presented in Table 2, and particle size distribution of the aggregates is shown in Fig. 1. As can be seen from Fig. $3 a$ and $b$, the SFS contains both angular and rounded particles with smooth surface texture. The SFS is classified as clay-bonded (green) sand and therefore has no potential leaching organic compounds. In general, foundries use screening systems and magnetic separators to segregate reusable sand

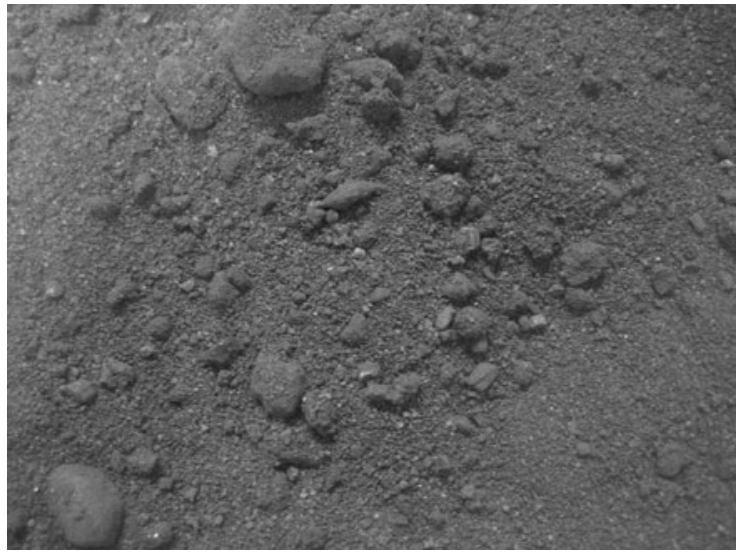

Fig. 2 Appearance of SFS

Table 2 Chemical composition of SFS, \%

\begin{tabular}{ccccccccc}
\hline $\mathrm{SiO}_{2}$ & $\mathrm{Al}_{2} \mathrm{O}_{3}$ & $\mathrm{Fe}_{2} \mathrm{O}_{3}$ & $\mathrm{MgO}$ & $\mathrm{CaO}$ & $\mathrm{Na}_{2} \mathrm{O}$ & $\mathrm{K}_{2} \mathrm{O}$ & $\mathrm{TiO}_{2}$ & $\mathrm{P}_{2} \mathrm{O}_{5}$ \\
\hline 76.0 & 4.45 & 5.06 & 1.98 & 3.56 & 0.38 & 1.20 & 0.17 & 0.04 \\
\hline $\mathrm{MnO}$ & $\mathrm{Cr}_{2} \mathrm{O}_{3}$ & $\mathrm{~V}_{2} \mathrm{O}_{5}$ & $\mathrm{LoI}$ & $\mathrm{Ni}$ & $\mathrm{Cu}$ & $\mathrm{Pb}$ & $\mathrm{Zn}$ & $\mathrm{Cr}$ \\
\hline 0.46 & 0.04 & $<0.01$ & 5.85 & $<0.01$ & 0.02 & 0.03 & 0.05 & $<0.05$ \\
\hline
\end{tabular}

from other wastes such as metals. In this way, they can ensure that SFS is largely free from excess contaminants and qualifies as a non-hazardous industrial by-product [2, 13]. Moreover, Winkler and Bolshakov [14] stated that based on the results of Toxicity Characteristics Leaching Procedure (TCLP) most of the leachate concentrations measured was lower than federal drinking water standards, indicating that it is generally safe to reuse these sands.

\subsection{SCC mixtures and tests done}

Sixteen SCC mixtures were prepared with the proportions summarized in Table 3 . The PC in the mixtures was replaced with FA at 0, 30, 50 and 70\% by mass. For each FA replacement level, about 0,25 , 50 and $100 \%$ of sand by volume was replaced with SFS. For all mixtures, the total amount of binder $(\mathrm{PC}+\mathrm{FA})$ and the water to binder ratio $(\mathrm{w} / \mathrm{b})$ were kept constant at $450 \mathrm{~kg} / \mathrm{m}^{3}$ and 0.40 , respectively. HRWR was added by an amount to secure the concrete be SCC considering the specifications of The European Guidelines for Self Compacting Concrete [15]. 

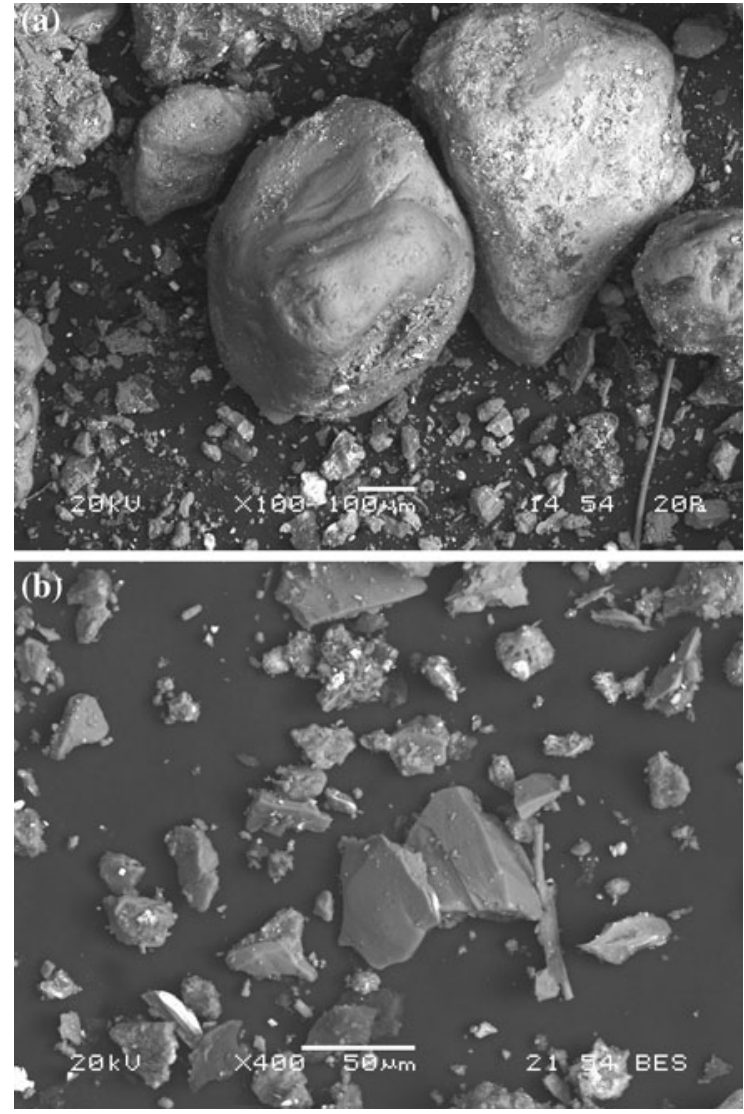

Fig. 3 a Rounded SFS particles. b Angular SFS particles

All concrete mixtures were mixed for 7 min with a 70-1 rotating planetary mixer. After mixing, slump flow diameter, slump flow time, and V-funnel flow time were determined by following the tests protocols in The European Guidelines for Self Compacting Concrete [15]. Fresh mixtures were visually inspected for segregation or bleeding. Rheological parameters (yield stress and relative viscosity) of the mixtures were determined according to Bingham model by a co-axial cylinder system rheometer, which is fully controlled by a software [16]. The outer and inner cylinders had radii of 14.5 and $10.0 \mathrm{~cm}$, respectively. Torque was measured from the inner cylinder as the outer cylinder rotated at variable angular velocity. Vertical ribs on the inner cylinder reduced the effect of wall slippage at the interfacial zone between the cylinder surface and fresh concrete. Torque and rotational speed values were automatically recorded by the software.

$100 \times 200 \mathrm{~mm}$ cylinder specimens from each fresh SCC mixture were prepared to determine compressive strength, rapid chloride permeability and volume of permeable pores. All specimens were cast in one layer without any compaction. At the age of $24 \mathrm{~h}$, the specimens were removed from their moulds and stored in moist a room $(\mathrm{RH}>98 \%)$ at $23 \pm 2{ }^{\circ} \mathrm{C}$ for 7,28 and 90 days.

Three $70 \times 280 \mathrm{~mm}$ cylinders were also prepared for drying shrinkage tests. Drying shrinkage of these specimens was measured at 7, 28, 56 and 90 days after an initial curing of 1 day in the mould, 27 days in lime saturated water, and subsequent storage in laboratory at $23 \pm 2{ }^{\circ} \mathrm{C}$, and $50 \pm 4 \%$ relative humidity. Permeation properties were determined at 28 and 90 days, using the volume of permeable pores (VoPP) test and rapid chloride permeability test (RCPT) in accordance with ASTM C642 and ASTM C1202 specifications, respectively.

The VoPP test determines the concrete absorption expressed as percentage of the absorbed water over the dry mass of concrete. Four $\varnothing 100 \times 50$-mm disc specimens were dried in an oven at $105 \pm 5^{\circ} \mathrm{C}$ to constant weight. The specimens were then immersed in tap water and weighed every $24 \mathrm{~h}$ to check the increase in mass, until the increase in mass was less than $0.5 \%$ of the heavier mass which defines the saturation stage. In this test, water absorption occurs only in pores that were emptied during drying and filled with water during immersion. Because these pores can be considered permeable, the absorption of the concrete sample after immersion until saturation indicates its level of permeability. This test, determined the total volume of permeable pores. (It is worth to state that drying at $105^{\circ} \mathrm{C}$ may cause some damage/alterations to the microstructure. Consequently, the water absorption has to be analyzed with care, as it is giving results for damaged materials. However, the reason why such severe conditions were applied is that following a standard procedure (ASTM C 642 in this case) is always advantageous to enable different researchers to compare their results.)

A water saturated, $50 \mathrm{~mm}$ thick, $100 \mathrm{~mm}$ diameter concrete specimen was obtained from the $100 \times 200$ mm cylinder specimens. A rapid chloride permeability test was performed on the specimen by subjecting it to a $60 \mathrm{~V}$ applied DC voltage for $6 \mathrm{~h}$. In this test, one end of the specimen is placed in contact with a $0.3 \mathrm{M} \mathrm{NaOH}$ solution, the other end with a $3.0 \%$ $\mathrm{NaCl}$ solution. The total charge passed during $6 \mathrm{~h}$ is 
Table 3 SCC mixture proportions

\begin{tabular}{|c|c|c|c|c|c|c|c|c|}
\hline Mix ID & $\begin{array}{l}\mathrm{PC} \\
\left(\mathrm{kg} / \mathrm{m}^{3}\right)\end{array}$ & $\begin{array}{l}\text { FA } \\
\left(\mathrm{kg} / \mathrm{m}^{3}\right)\end{array}$ & $\begin{array}{l}\text { Sand } \\
\left(\mathrm{kg} / \mathrm{m}^{3}\right)\end{array}$ & $\begin{array}{l}\text { SFS } \\
\left(\mathrm{kg} / \mathrm{m}^{3}\right)\end{array}$ & $\begin{array}{l}\text { Coarse aggregate } \\
\left(\mathrm{kg} / \mathrm{m}^{3}\right)\end{array}$ & $\begin{array}{l}\text { Water } \\
\left(\mathrm{kg} / \mathrm{m}^{3}\right)\end{array}$ & $\begin{array}{l}\mathrm{SP} \\
\left(\mathrm{kg} / \mathrm{m}^{3}\right)\end{array}$ & $\begin{array}{l}\text { Unit weight } \\
\left(\mathrm{kg} / \mathrm{m}^{3}\right)\end{array}$ \\
\hline OFA-OSFS & 450 & 0 & 850 & 0 & 850 & 180 & 2.03 & 2333 \\
\hline 0FA-25SFS & 450 & 0 & 638 & 201 & 850 & 180 & 3.33 & 2322 \\
\hline 0FA-50SFS & 450 & 0 & 425 & 402 & 850 & 180 & 5.63 & 2313 \\
\hline 0FA-100SFS & 450 & 0 & 0 & 803 & 850 & 180 & 12.88 & 2296 \\
\hline 30FA-0SFS & 315 & 135 & 831 & 0 & 831 & 180 & 1.80 & 2294 \\
\hline 30FA-25SFS & 315 & 135 & 623 & 196 & 831 & 180 & 3.15 & 2283 \\
\hline 30FA-50SFS & 315 & 135 & 415 & 393 & 831 & 180 & 4.90 & 2274 \\
\hline 30FA-100SFS & 315 & 135 & 0 & 785 & 831 & 180 & 7.60 & 2253 \\
\hline 50FA-0SFS & 225 & 225 & 818 & 0 & 818 & 180 & 1.58 & 2267 \\
\hline 50FA-25SFS & 225 & 225 & 614 & 193 & 818 & 180 & 2.53 & 2257 \\
\hline 50FA-50SFS & 225 & 225 & 409 & 386 & 818 & 180 & 3.88 & 2247 \\
\hline 50FA-100SFS & 225 & 225 & 0 & 773 & 818 & 180 & 5.20 & 2226 \\
\hline 70FA-0SFS & 135 & 315 & 805 & 0 & 805 & 180 & 1.15 & 2241 \\
\hline 70FA-25SFS & 135 & 315 & 604 & 190 & 805 & 180 & 2.10 & 2231 \\
\hline 70FA-50SFS & 135 & 315 & 403 & 380 & 805 & 180 & 3.05 & 2221 \\
\hline 70FA-100SFS & 135 & 315 & 0 & 760 & 805 & 180 & 3.22 & 2198 \\
\hline
\end{tabular}

then determined. The total charge passed, in coulombs, measures the concrete's ability to resist chloride ion penetration. As more chloride ions migrate into the concrete, more current can pass through, and the total charge passed during $6 \mathrm{~h}$ increases. A high value for total charge passed indicates that the concrete is highly penetrable.

\section{Results and discussion}

\subsection{Fresh properties}

The results for slump flow diameter, slump flow time, V-funnel flow time, and rheological parameters (yield stress and relative viscosity) of the SCC mixtures are shown in Table 4. The European Guidelines for Self Compacting Concrete [15] limit slump flow diameter to a minimum of $550 \mathrm{~mm}$ and $\mathrm{V}$-funnel flow time to a maximum of $25 \mathrm{~s}$. As illustrated in Table 4, all of the mixtures satisfy these requirements. Moreover, no visible segregation or bleeding was observed in the fresh mixtures, as can be seen from Fig. 4 (spread of 50FA-50SFS mixture), which shows a typical example of the uniform spread of SCC mixtures. The conclusion, therefore, is that SCC with proper fresh properties can successfully be produced with SFS and FA.
Generally, for a given FA content, the superplasticizer requirement increases with SFS content for fresh properties like slump flow diameter. In the same way, V-funnel flow time generally increased with an increase in SFS content. The increase in superplasticizer requirement or loss in consistency can be attributed to the finer grain size distribution of SFS over that of regular sand (Fig. 1). Angular particles of SFS that replaced the regular rounded sand also caused decreased workability. Another reason for the increase in superplasticizer requirement with the increase in SFS content can be due to the chemical/mineralogical nature of SFS: Silica sand which is present in the SFS is hydrophilic and consequently attracts water to it surface. Moreover, the presence of clay in clay-bonded (green) sand, as is the case in this study, can also cause lower workability $[17,18]$.

V-funnel flow time of the concretes with no fly ash was longer than that of the mixtures with fly ash. Similarly, slump flow time of the $0 \%$ FA mixtures was higher than that of the mixtures containing FA. As known, both V-funnel flow time and slump flow time are related with the viscosity, and these results are confirmed by the viscometer tests. Another discussion that can be made from Table 4 is that in almost all cases, V-funnel flow time and slump flow time got lower when the FA replacement reached $70 \%$. 
Table 4 SCC fresh properties

\begin{tabular}{llllll}
\hline Mix ID & $\begin{array}{l}\text { Slump flow } \\
\text { diameter }(\mathrm{mm})\end{array}$ & $\begin{array}{l}\text { Slump flow } \\
\text { time }(\mathrm{s})\end{array}$ & $\begin{array}{l}\text { V-funnel } \\
\text { flow time }(\mathrm{s})\end{array}$ & $\begin{array}{l}\text { Yield } \\
\text { stress (Pa) }\end{array}$ & $\begin{array}{l}\text { Relative } \\
\text { viscosity (Nm s) }\end{array}$ \\
\hline 0FA-0SFS & 605 & 3.83 & 7.7 & 23 & 4.06 \\
0FA-25SFS & 657 & 2.02 & 5.6 & 18 & 3.75 \\
0FA-50SFS & 655 & 2.71 & 7.3 & 15 & 5.66 \\
0FA-100SFS & 675 & 1.70 & 9.0 & 6 & 6.01 \\
30FA-0SFS & 707 & 3.10 & 2.6 & 8 & 1.36 \\
30FA-25SFS & 710 & 1.50 & 4.6 & 4 & 1.26 \\
30FA-50SFS & 685 & 0.91 & 3.1 & 20 & 3.22 \\
30FA-100SFS & 745 & 1.10 & 7.0 & 4 & 5.12 \\
50FA-0SFS & 612 & 1.60 & 3.5 & 19 & 3.15 \\
50FA-25SFS & 605 & 2.20 & 5.5 & 70 & 3.99 \\
50FA-50SFS & 717 & 1.10 & 1.9 & 5 & 0.76 \\
50FA-100SFS & 739 & 1.30 & 6.5 & 5 & 4.44 \\
70FA-0SFS & 695 & 1.20 & 2.5 & 8 & 2.24 \\
70FA-25SFS & 615 & 1.50 & 3.5 & 48 & 3.02 \\
70FA-50SFS & 702 & 0.90 & 2.4 & 5 & 1.05 \\
70FA-100SFS & 710 & 0.90 & 2.5 & 6 & 3.12 \\
\hline
\end{tabular}

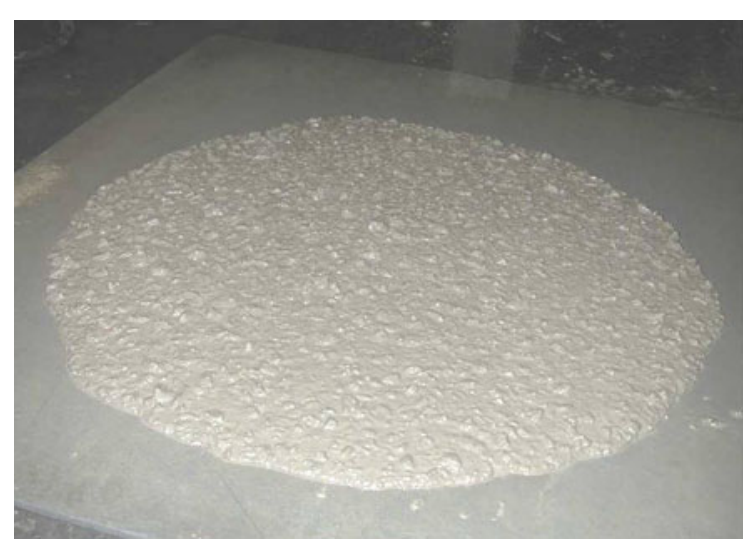

Fig. 4 An example for uniform spread of SCC

Yield stress values of all mixture were quite low, which is essential for high deformability of SCC. Previous studies showed that yield stress of SCC is generally less than $100 \mathrm{~Pa}$ to enable good deformability [19]. Therefore, being the maximum yield stress $70 \mathrm{~Pa}$, the yield stress values are compatible with the literaure. Relative viscosity values are also comparable with the literature: Jau and Yang [20] produced several SCC mixtures with Class F fly ash, ground granulated blast furnace slag and several types of viscosity modifiers, and found that the relative viscosity values range between 1.42 and $5.42 \mathrm{Nm} \mathrm{s}$.
Şahmaran et al. [21] reported relative viscosities ranging between 2.78 and $11.48 \mathrm{Nm}$ s. In a study of Erdem et al. [22], relative viscosity ranged between 0.89 and $2.12 \mathrm{Nm} \mathrm{s}$. It has to be noted that both yield stress and relative viscosity measurements are highly dependent on the rheometer type and the values can differ significantly with rheometer type. Nevertheless, as seen, the values in this study, which lie between 4-70 Pa for yield stress and between 0.76-6.01 Nm s for relative viscosity, are comparable with the previous studies. The change of yield stress with FA and SFS was not clear from the data obtained. (Using SFS or FA sometimes increased and sometimes decreaed the yield stress). However, it can be said that for a given FA content, SFS increased the relative viscosity of the mixtures, especially beyond $50 \%$ replacement levels, due to the reasons already explained above. As predicted from conclusions drawn in previous studies [21, 23], relative viscosity showed parallel results with V-funnel flow time, and accordingly, relative viscosity was highest for $100 \%$ SFS replacement.

It has to be noted that the minimum value of coefficient of determination $\left(R^{2}\right)$ obtained in the determination of rheological parameters according to Bingham model was 0.942. Therefore, it can be stated that the rheological behavior was linear and discrepancy from Bingham model was very little. 


\subsection{Compressive strength}

The effect of SFS on compressive strength at 7, 28 and 90 days is shown Fig. 5a, b and c, respectively. Standard deviations for each compressive strength value were also shown in all plots. The statistical analyses showed that coefficient of variation was less $10 \%$ for all of the data. The maximum value of coefficient of variation was $8.5 \%$, indicating that the data showed little dispersion and the discussions below have strong basement.

In all curing ages, the compressive strength of the control mixtures with 0\% SFS was higher than the
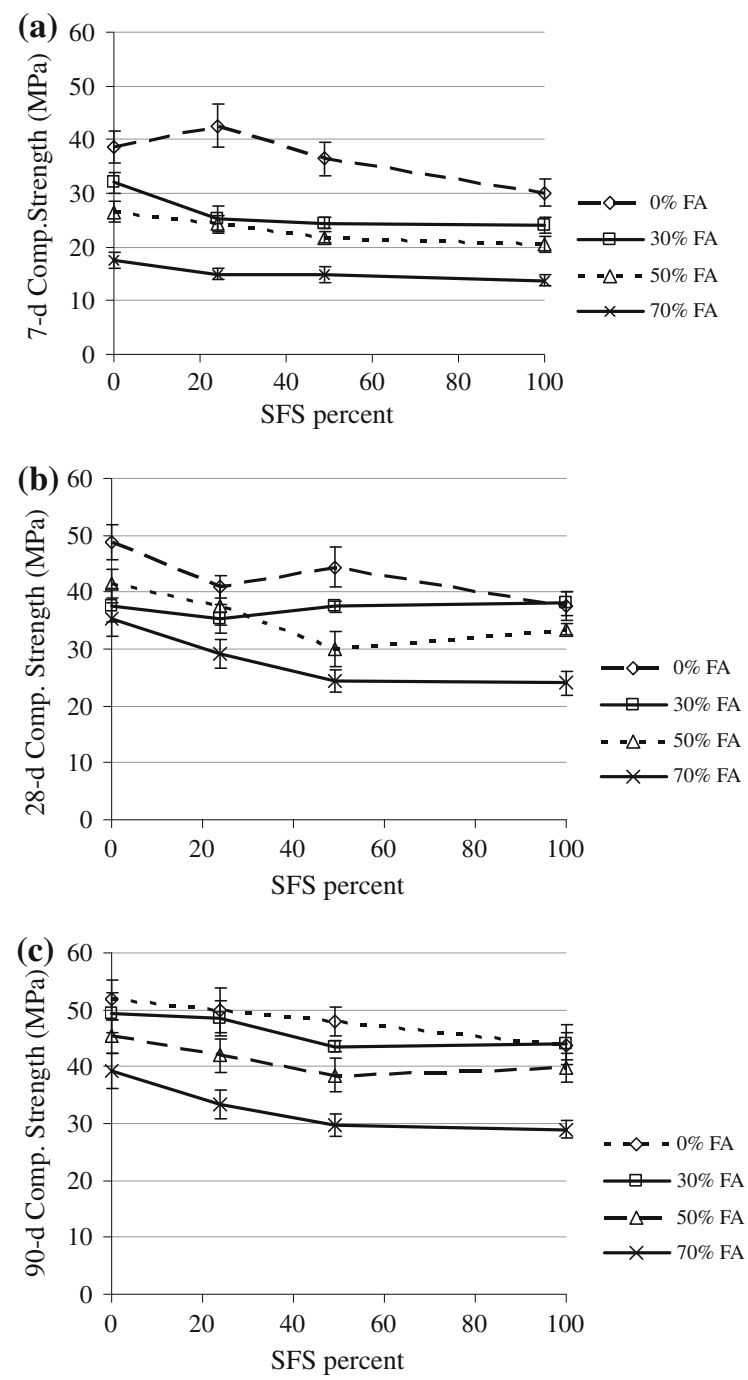

Fig. 5 a Compressive strength at 7 days. b Compressive strength at 28 days. c Compressive strength at 90 days one containing SFS. However, when the strengths at 7 and 90 days were compared, it was observed that for a given FA content (except 70\%), the SFS-related decrease in strength was lower at 90 days than at 7 days. For example, in $30 \%$ FA concretes, the strengths of 0 and $100 \%$ SFS at 7 days were 32.0 and $24.1 \mathrm{MPa}$, respectively, a decrease of $25 \%$. At 90 days, the strength had decreased by only $11 \%$, from 49.4 to $44.0 \mathrm{MPa}$. Therefore, the beneficial effects of FA observed at later ages partially compensated for the negative impact of SFS on strength. (For 70\% FA content, strength loss due to SFS replacement were comparable at 7 and 90 days.)

Loss of strength due to SFS replacement has also been noted by other researchers [6, 7] although Siddique et al. [1, 5] reported improvement in compressive strength with an increase in SFS amounts up to $30 \%$. Kraus et al. [10] reported the possibility of a reaction between relic organic materials in SFS (from processing of metals) and chemical admixtures such as HRWRs and viscosity-modifying admixtures, that may cause an increase in air content, and result in strength loss.

For a given SFS content, the use of FA reduced strengths, especially at 7 days. However, the difference between the concretes with FA and without FA was smaller at 90 days. In fact, $0 \%$ FA and $30 \%$ FA concretes showed almost the same strengths at all SFS contents (Fig. 5c), which can be explained by the slow, ongoing pozzolanic reactions of FA during specimen curing. $70 \%$ replacement of PC with FA, however, reduced strengths significantly at both ages.

Although both SFS and FA were found to reduce strengths, producing SCC with compressive strengths around $40 \mathrm{MPa}$ at 28 days and $50 \mathrm{MPa}$ at 90 days was still possible by using a combination of SFS and FA. With the exception of $70 \%$ FA concretes, almost all specimens had strengths higher than $40 \mathrm{MPa}$. This holds true even at $100 \%$ SFS replacement level.

\subsection{Drying shrinkage}

The effect of FA content on drying shrinkage at several ages was shown in Fig. 6a for a constant SFS amount $(50 \%)$. (The figures for other SFS contents were similar and therefore only one figure was selected to represent the others.) The figure shows the standard deviation of the data, too. According to the figure, FA reduced the drying shrinkage at all ages, as 

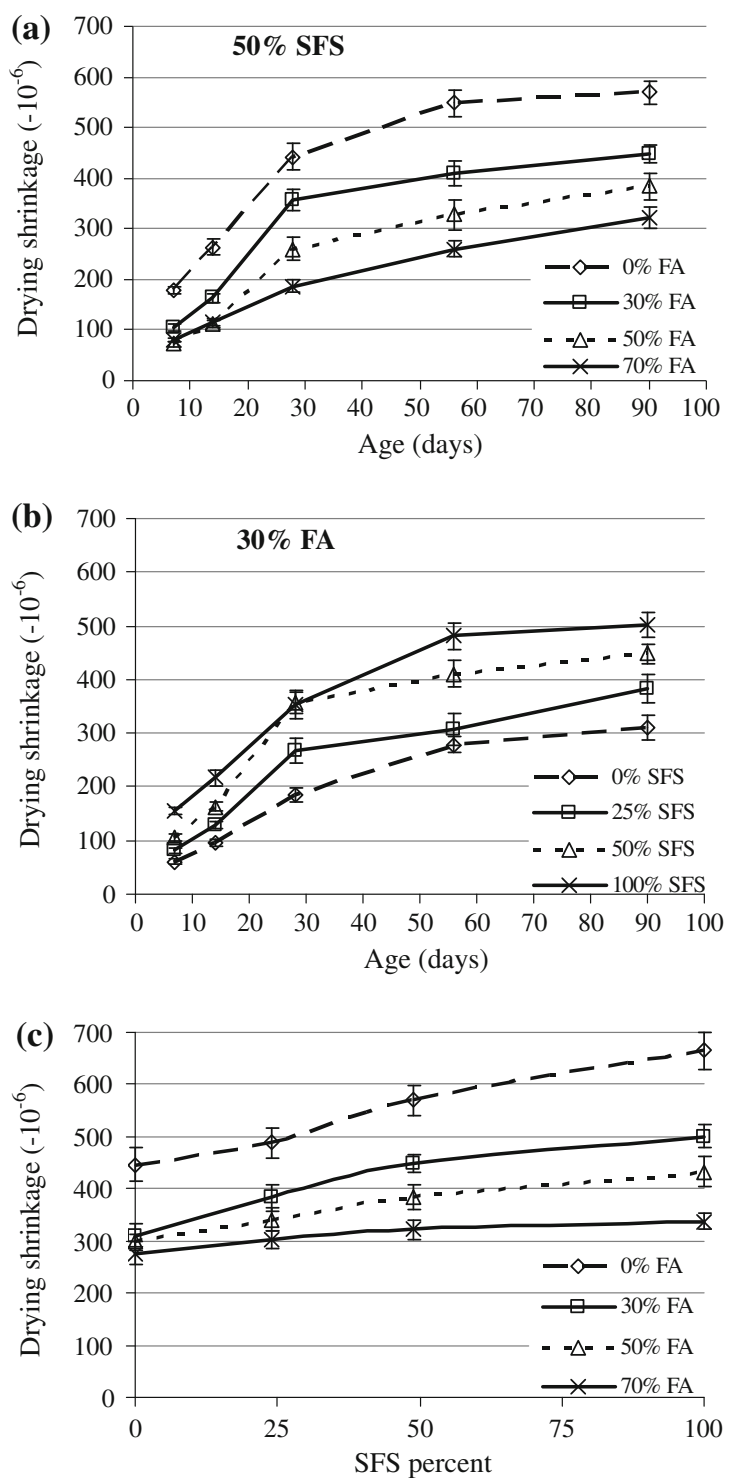

Fig. 6 a Effect of FA on drying shrinkage. b Effect of SFS on drying shrinkage. c Drying shrinkage at 90 days

noted in the literature $[11,21]$. The reduction was higher as the FA content increased. The role of FA in reducing drying shrinkage can be explained by matrix densification due to FA addition, which may prevent internal moisture evaporation [24]. Matrix densification is typically attributed to the shape, pozzolanic property, and micro-filler effect of FA. Unhydrated FA particles can also serve as fine aggregates to restrain shrinkage deformation [21, 25].

Figure $6 \mathrm{~b}$ shows the effect of SFS content on drying shrinkage at several ages for a selected FA content. (The behavior was similar for the other FA contents.) The figure clearly indicates that as the SFS amount increased, drying shrinkage increased at all ages. However, thanks to simultaneous use FA and SFS that reduces back the drying shrinkage of the mixtures. For example, considering the drying shrinkage values at 90 days (Fig. 6c), 0\% FA concretes showed highest shrinkage values for all SFS contents. On the other hand, incorporation of even $30 \%$ FA reduced the shrinkage values significantly. Reduction was higher as the FA content increased (Fig. 6c).

The increase in drying shrinkage due to partial or full replacement with SFS has also been noted by other researchers [6,7]. Khatib and Ellis [6] replaced standard sand with SFS by 25, 50, 75 and $100 \%$, and observed that drying shrinkage increased along with SFS content. Naik et al. [7] investigated drying shrinkage of concrete blocks, bricks and paving stones by replacing sand with bottom ash and SFS. The concretes (both blocks and bricks) made with SFS or bottom ash showed higher shrinkage than those made with standard sand, a result that is consistent with the current study. The shrinkage of the blocks and bricks containing SFS was higher than that of the concretes containing bottom ash.

The effect of SFS on drying shrinkage is most probably related to its fineness. As indicated in Fig. 1, the SFS used in this study is finer than regular sand. It is worth noting that a recent study showed that aggregate size affects drying shrinkage [25]; the use of a larger aggregate reduced drying shrinkage due its restraining effect. Another reason for the higher shrinkage of SFS concretes may be that SFS has a higher water absorption capacity than regular sand, leading to the conclusion that the higher amount of water absorbed in regular sand is fed to the matrix over a longer period of time. In other words, since the aggregates store water, concrete made with them dries more slowly than that made with SFS.

\subsection{Rapid Chloride Permeability (RCP)}

The results of RCP tests performed at 28 and 90 days are shown in Fig. $7 \mathrm{a}$ and b, respectively. They are expressed in terms of the total electrical charge in coulombs, which provides an indirect measure of the resistance of SCC mixtures to chloride ion penetration. Much like the findings of previous studies [11, 

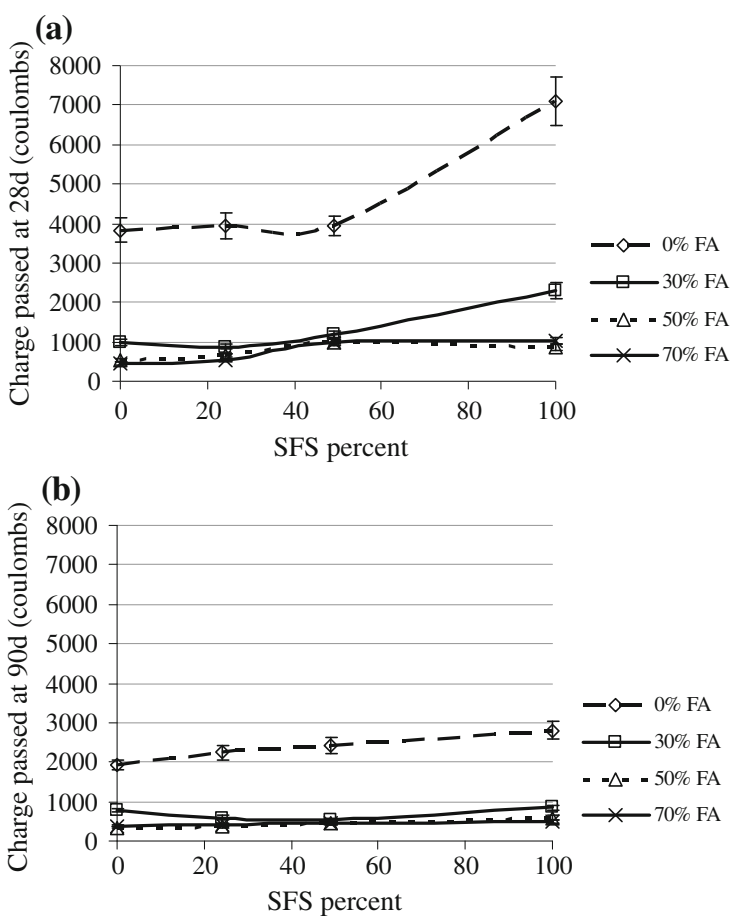

Fig. 7 a Rapid chloride permeability at 28 days. b Rapid chloride permeability at 90 days

26], these figures show that the use of FA significantly reduced the chloride permeability of the hardened SCC mixtures when compared to the control concretes with 0\% FA. For any given SFS content, the reduction was generally greater than $80 \%$ for FA replacement levels of 50 and $70 \%$ at both 28 and 90 days.

The lower RCP of FA concretes can be attributed to the more compact structure of the paste, which is a result of finer FA particles than PC (filler effect) and pozzolanic reactions of FA. In literature, it is stated that these effects reduce the pore size and the thickness of the transition zone between the aggregate and surrounding cementitious matrix, resulting in lower permeability [27, 28]. Permeability was lower at 90 days than at 28 days, as expected due to the hydration of $\mathrm{PC}$ and pozzolanic reactions of FA. The reduction ranged between $15 \%$ (for $70 \% \mathrm{FA}$ and $0 \%$ SFS concrete) and 63\% (for 30\% FA and $100 \%$ SFS concrete).

Although Fig. 7a and b show a detrimental effect of SFS on chloride permeability, it is minor when the mixtures contain FA (especially when the SFS amount is lower than or equal to 50\%). For example, the charge passed at 90 days ranged between 1,931 and 2,800 coulomb for $0 \%$ FA concretes, while it was between 345 and 852 coulomb for those containing FA. The benefits of simultaneous use of SFS and FA on RPC was an expected result since this benefit was observed also on compressive strength results, as discussed previously.

The results also showed that the rapid chloride permeability of most concretes containing FA and SFS was below 750 coulomb at 90 days, which indicate relatively high-quality SCC mixtures from rapid chloride permeability standpoint (ASTM C 1202 classifies the chloride ion penetrability of a concrete as "very low" as long as the charge passed is between 100 and 1,000 coulomb).

It should also be noted that the RCPT results depends on the electrical conductivity of pore solution, which is determined by the composition of the pore solution. The electrical conductivity or RCPT value of a concrete can be reduced by lowering the alkalinity of concrete pore solution. When FA with low lime and low alkali contents, as in this study (Table 1), is used to partially replace PC, the concentration of alkali ions and associated hydroxyl ions in the pore solution generally decreases significantly, and the extent of this reduction depends also on FA replacement level [29]. Because of the expected differences in electrical resistance between SCC mixtures, however, the electrical conductivity values may also be different. As a result, the RCPT values may reflect this difference and therefore should be interpreted with care.

\subsection{Volume of Permeable Pores (VoPP)}

This test is based on water flow into unsaturated concrete through large connected pores. The effect of SFS on the volume of permeable pores was similar at 28 and 90 days as shown in Fig. 8 a and b. For SFS replacement levels up to $50 \%$, the volume of permeable pores did not change significantly with SFS amount. This is a promising result that could encourage the use of SFS in making green SCC without increasing permeable pore volume and threatening durability of hardened mixtures.

At both 28 and 90 days, the concretes containing $0 \%$ FA showed higher volumes of permeable pores than those made with FA. In other words, FA reduced 

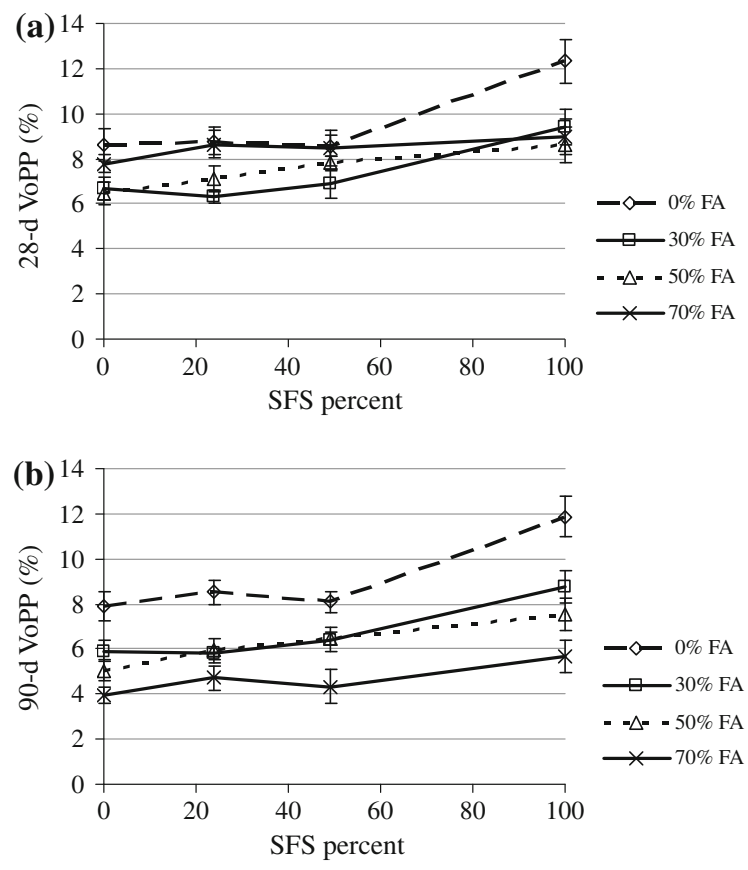

Fig. 8 a Volume of permeable pores at 28 days. b Volume of permeable pores at 90 days

permeability which is so important for the durability of the concretes. This result confirms the findings of previous studies $[11,21]$. The effect of FA was not as significant as the RCP results. The beneficial effect of FA can be explained by the denser matrix obtained from its filler effect and pozzolanic reactions, which leads to a reduction in pore sizes and micro-cracking in the transition zone, as stated in the literature [28]. The effect of pozzolanic reactions of FA is significant when the results for 28 and 90 days are compared; while the decrease of VoPP in time was around 6\% for $0 \%$ FA concretes, it was around $45 \%$ for $70 \%$ FA concretes.

The compensating effect of FA can be seen again in the VoPP results. With the exception of a few cases, almost all of the mixtures prepared with FA had lower VoPP than the concretes with 0\% SFS, regardless of the level of SFS content.

\subsection{Economical and environmental considerations}

It has been shown above that strengths over $40 \mathrm{MPa}$ can be reached even at $100 \%$ replacement of natural sand with SFS. Assuming that SFS can be obtained from the foundry with no material cost, the cost of fine aggregate can be saved. Moreover, satisfactory fresh and hardened properties can also be obtained with high volumes of (up to 70\%) FA replacement of cement. Therefore, the cost of concrete is further reduced since cement is the most expensive component of concrete. Considering the economy in a wider scale, the disposal cost of these waste materials (both FA and SFS) is reduced through recycling these waste materials in concrete. In addition, the beneficial effects of FA replacement on durability of concrete is known for several decades and much work in the literature proves this fact. The longer service life of structures made with such concretes results in reductions in the repair costs and eventually provides savings to the national economy.

Regarding the ecological aspects, the use of these waste materials in concrete has several advantages for the industry and public, which can be listed as:

- Use of SFS as replacement material for sand helps to conserve our natural resources.

- Use of FA reduces the clinker production and consumption of the raw materials obtained from nature.

- Huge stock piles of these wastes will be prevented.

- Carbon dioxide emission in the cement plants can be reduced by use of FA as a cement replacement material. (It is worth to note that one ton of cement production causes almost one ton carbon dioxide emission to the atmosphere.)

- Energy required for cement production can be reduced to a great extent, which not only provides reductions in cost but also reduce the consumption of our natural resources.

\section{Conclusions}

(1) SCC mixtures with low yield stress and adequate fresh properties such as slump flow diameter, slump flow time, V-funnel flow time, and relative viscosity can be produced by replacing sand with SFS.

(2) Although SFS and FA reduce the strengths, it is still possible to produce SCC with compressive strengths around $40 \mathrm{MPa}$ at 28 days and 
$50 \mathrm{MPa}$ at 90 days by using both SFS and FA. Strengths over $40 \mathrm{MPa}$ can be reached even at $100 \%$ SFS replacement.

(3) An increase in SFS content increases drying shrinkage. However, the rate of increase with SFS content decreases with an increase in FA amount.

(4) Although SFS has a detrimental effect on chloride permeability, this effect is very minor (especially when the SFS amount is $50 \%$ or less) provided that the mixtures contain FA. In such mixtures, total charge passed below 900 coulombs at 90 days.

(5) $100 \%$ SFS replacement increases VoPP significantly. However, when the SFS replacement level is $50 \%$ or lower, the volume of permeable pores does not change significantly with SFS amount.

(6) Up to $100 \%$ replacement of sand with SFS and up to $70 \%$ replacement of Portland cement with FA can enable the production of cost-effective, green SCC mixtures with proper fresh, mechanical and durability properties. The beneficial effects of FA can compensate for some possible detrimental effects of SFS.

Acknowledgments The authors gratefully acknowledge the financial assistance of the Natural Sciences and Engineering Research Council (NSERC) of Canada, and the Canada Research Chair Program.

\section{References}

1. Siddique R, de Schutter G, Noumowe A (2009) Effect of used-foundry sand on the mechanical properties of concrete. Constr Build Mater 23(2):976-980

2. Siddique R, Noumowe A (2008) Utilization of spent foundry sand in controlled low-strength materials and concrete. Resour Conserv Recycl 53(1-2):27-35

3. Naik TR (1989) Foundry industry by-products utilization. Report No. CBU-1989-01, Center for By-Products Utilization. College of Engineering and Applied Science, University of Wisconsin, Milwaukee

4. Naik TR, Singh SS, Tharaniyil MP, Wendorf RB (1996) Application of foundry by-product materials in manufacture of concrete and masonry products. ACI Mater J 93(1):41-50

5. Siddique R, Gupta R, Kaur I (2007) Effect of spent foundry sand as partial replacement of fine aggregate on the properties of concrete. In: 22nd Int conference on solid waste technology and management, Widener University, Philadelphia, USA, pp 1386-1396
6. Khatib JM, Ellis DJ (2001) Mechanical properties of concrete containing foundry sand. ACI Spec Publ SP200:733-748

7. Naik TR, Kraus RN, Chun YM, Ramme WB, Singh SS (2003) Properties of field manufactured cast-concrete products utilizing recycled materials. J Mater Civ Eng 15(4):400-407

8. Bakis R, Koyuncu H, Demirbas A (2006) An investigation of waste foundry sand in asphalt concrete mixtures. Waste Manag Res 24(3):269-274

9. Fiore S, Zanetti MC (2007) Foundry wastes reuse and recycling in concrete production. Am $\mathrm{J}$ Environ Sci 3(3):135-142

10. Kraus RN, Naik TR, Ramme BW, Kumar R (2009) Use of foundry silica-dust in manufacturing economical selfconsolidating concrete. Constr Build Mater 23(11): 3439-3442

11. Sahmaran M, Yaman IO, Tokyay M (2009) Transport and mechanical properties of self consolidating concrete with high volume fly ash. Cem Concr Compos 31(2):99-106

12. Bouzoubaa N, Lachemi M (2001) Self-compacting concrete incorporating high volumes of Class F fly ash: preliminary results. Cem Concr Res 31(3):413-420

13. Foundry Industry Recycling Starts Today (FIRST) (2004) Foundry sand facts for civil engineers. Federal Highway Administration Environmental Protection Agency, Washington

14. Winkler ES, Bolshakov AA (2000) Characterization of foundry sand waste. Chelsea Center for Recycling and Economic Development. University of Massachusetts at Lowell, Lowell

15. The European guidelines for self-compacting concrete: specification, production and use. EFNARC, May 2005, 63p, http://www.efnarc.org/pdf/SCCGuidelinesMay2005.pdf

16. Wallevik OH (2000) The BML viscometer, The viscometer 4. ConTec operating manual, version 2000, ConTec Ltd, pp 20-70

17. Tikalsky P, Gaffney M, Regan R (2000) Properties of controlled low-strength material containing foundry sand. ACI Mater J 97(6):698-702

18. Bhat ST, Lovell CW (1996) Design of flowable fill: waste foundry sand as a fine aggregate. Transp Res Rec 1546: 70-78

19. Esping O (2007) Early age properties of self-compacting concrete-effects of fine aggregate and limestone filler. $\mathrm{PhD}$ Thesis, Chalmers University of Technology, Sweden

20. Jau WC, Yang CT (2010) Development of a modified concrete rheometer to measure the rheological behavior of conventional and self-consolidating concretes. Cem Concr Compos 32:450-460

21. Şahmaran M, Yaman İÖ, Tokyay M (2007) Development of high-volume low-lime and high-lime fly-ash-incorporated self-consolidating concrete. Mag Concr Res 59(2): 97-106

22. Erdem TK, Khayat KH, Yahia A (2009) Correlating rheology of SCC to corresponding concrete-equivalent mortar. ACI Mater J 106(2):154-160

23. Lachemi M, Hossain KMA, Lambros V, Bouzoubaa $\mathrm{N}$ (2003) Development of cost-effective self-consolidating concrete incorporating fly ash, slag cement, or viscositymodifying admixtures. ACI Mater J 100(5):419-425 
24. Maslehuddin M, Saricimen H, Al-Mani A (1987) Effect of fly ash addition on the corrosion resisting characteristics of concrete. ACI Mater J 84(1):42-50

25. Şahmaran M, Lachemi M, Hossain KMA, Ranade R, Li VC (2009) Influence of aggregate type and size on ductility and mechanical properties of engineered cementitious composites. ACI Mater J 106(3):308-316

26. Shi C (2004) Effect of mixing proportions of concrete on its electrical conductivity and rapid chloride permeability test results. Cem Concr Res 34(3):537-545
27. Kuroda M, Watanabe T, Terashi N (2000) Increase of bond strength at interfacial transition zone by the use of fly ash. Cem Concr Res 30(2):253-258

28. Mehta PK, Monteiro PJM (2006) Concrete: microstructure, properties, and materials. McGraw-Hill, New York

29. Shehata MH, Thomas MDA, Bleszynski RF (1999) The effect of fly ash composition on the chemistry of pore solution. Cem Concr Res 29(12):1915-1920 